The problem of control is a formidable one. Cold storage merely delays but does not prevent enzymic deterioration, since enzyme reactions, like all other chemical reactions, are slowed but not stopped by lowering of temperature. Other standard methods, such as the addition of inhibitors or competitive sub. strates, are by no means universally applicable. Probably the most commonly used procedure is that of heat inactivation ('blanching'), but this can lead to unwanted structural changes in fruits and vegetables. At present there is no simple and universal solution.

It must be said that on one point the arrangement of the symposium was open to critical attack, namely, the lack of time available for free discussion. It is in this discussion that the value of a symposium such as this largely resides, both for the audience and for the contributors themselves. Arrangements had been made for the discussions to be opened by appropriate authorities and these authorities presented what virtually amounted to additional contributions, com- parable in weight and importance to those of the main contributors. On this account, the unscripted discussion was seriously restricted, particularly at the final session, and a number of potential questions had to remain unasked and unanswered. This was undoubtedly a loss and one can but ask that the point should be borne in mind when future symposia are being planned.

It is, however, pleasant to record that the symposium went with a swing to the end and was closed by the clock : there was no noticeable whittling away of the audience as special interests were disposed of. In its lighter moments the meeting considered future possibilities; these included 'tailored' enzymes for specified purposes and the application of enzymes to the restoration of flavour in over-cooked cabbage. It was also pointed out that one speaker had coined a new word-the verb "to enzyme". The purists may refuse to accept this innovation, but we must all accept the importance of the process it describes.

\title{
BIOCHEMICAL RESEARCH IN INDIA
}

\section{GOLDEN JUBILEE SYMPOSIUM}

\begin{abstract}
A SERIES of symposia was organized by the Department of Biochemistry, Fermentation and Pharmacology Laboratories of the Indian Institute of Science, as part of the celebrations of the golden jubilee of the Institute, during August 28-30, and was attended by more than two hundred scientists, including fifty delegates representing important centres of biochemical research in the country. The subjects covered were "Biology and Biochemistry of Micro-organisms", "Enzymes" and "Vitamins".

The symposia were inaugurated by Dr. S. Bhagavantam, the director of the Indian Institute of Science, and the first day of the session was presided over by Major-General S. L. Bhatia, who spoke on the "Progress of Physiology and Biochemistry in India". Prof. P. S. Sarma, who presided over the proceedings of the socond day, outlined the contributions in enzyme chemistry made by the late Prof. K. V. Giri (see Nature, 182, 1201 ; 1958). Dr. V. N. Patwardhan, who took the chair on the third and final day of the symposium, gave an address on the mode of action of vitamin $\mathrm{D}$ on which he and his group have been working for the past two decades. $\mathrm{He}$ and his collaborators have adduced experimental evidence to show that vitamin $\mathrm{D}$ acts presumably by promoting the synthesis of citric acid in the epiphyseal cartilage. Dr. V. Subrahmanyan, director of the Central Food Tochnological Research Institute, Mysore, who was professor of biochemistry in the Indian Institute of Science from 1931 until 1949, reviewed the work done in the department during his regime. He gave a bricf account of the development of the Bangalore process of composting, the elucidation of the principles of sewage purification, the preparation of a material from paddy husk for defluorinating fluoride-containing waters and the preparation of insulin and other hormones from slaughter-house material and vegetable 'milk' from soya bean. Prof. M. Sreenivasaya, who was one of the pioneers in enzyme chemistry during the early years of the Biochemistry Department, described the elegant method developed by him for the study
\end{abstract}

of enzymes both by the ultra-micro- as well as by micro-dilatometric methods.

Sixty-nine original research papers were presented at the symposia, and only a selection can be mentioned here.

M. G. Bhat, of the Indian Institute of Science, read a paper on the nutrition and metabolism of Pseudomonas convexa var. hippuricum representing the work done by her in collaboration with Drs. T. Ramakrishnan and J. V. Bhat. Dotailed investigations with regard to the nutritional requirements and metabolic pathways of this organism, which was isolated from soil using the enrichment culture technique, were outlined and a new pathway of benzoate breakdown by the bacteria involving salicylate, a mechanism different from the classical scheme of the metabolism of the aromatic ring, described. M. K. Subramanyam (Indian Institute of Science) gave a résumé of his studies on the eytology of yoast, which included the demonstration of the presence of a nucleus and a vacuole as well as the occurrence of nuclear and vacuolar membranes in the yeast cell. He also pointed out the general similarity of the structures of yeast and plant nuclei.

M. Chakravorty and D. P. Burma, of the Bose Institute, Calcutta, presented a paper on "Microbial Synthesis of Protein in Relation to the Biogenesis of Nucleic Acids". Using phosphorus-32 and sulphur-35, they have shown that, in the resting cell of Azotobacter vinelandii, conditions under which nucleic acid synthesis is inhibited lead to a docrease in protein synthesis. On the contrary, it was found that the incorporation of phosphorus-32 into the nucleic acid continued in an uninterrupted manner even when protein synthesis was inhibited. P. S. Sarma and co-workers, of the University Biochemical Laboratory, Madras, working on metal requirements of nicotinamide deaminases, have investigated the inhibition by metal-chelating agents of nicotinamidedeamidating systems in cell-free extracts of micro. organisms and the soluble fractions of pigeon liver. A study of the reversal of the inhibition, produced 
by $\alpha$ - $\alpha^{\prime}$-dipyridyl with various metal ions, has shown that the enzyme systems in the insect Corcyra cephalonica St., pigeon liver and chick kidneys are reactivated by $\mathrm{Fe}^{++}$, that in $A$. niger by $\mathrm{Mg}^{++}$and the one in $N$. crassa by $\mathrm{Mn}++$.

The detection and purification of a stereo-specific dihydrolipoic acid dehydrogenase formed the subjectmatter of an interesting paper by D. K. Basu and D. P. Burma, of the Bose Institute, Calcutta. The enzyme, which was purified 60-70-fold, was found to be diphosphopyridine nucleotide-linked and specific for dihydrolipoic acid and its amide. The reaction was irreversible when tested with lipoic acid as the substrate. I. S. Bhatia and co-workers, of the Tocklai Experimental Station, Cinnemara, Assam, gave an account of their work on the transglycosidase present in tea leaves. This enzyme reacted with maltose with the formation of maltotriose, maltotetrose and glucose. With arabinose as the acceptor of glucosyl residues and maltose as the donor, a disaccharide containing glucose and arabinose was formed.

The purification and properties of glutamicoxalacetic transaminase from ox brain and from human brain were described by T. N. Pattabhiraman and B. K. Bachhawat, of the Christian Medical College, Vellore. A 30-40-fold purification of the enzyme was achieved by fractionating the initial extract with alcohol, $\mathrm{Zn}++$ and ammonium sulphate. The purified ox-brain transaminase showed complete dependence on pyridoxal phosphate for its activity.

A new type of enzymatic transamination reaction in which glyoxylate transaminates with a number of amino-acids to produce glycine was reported by L. V. S. Sastry and T. Ramakrishnan (Indian Institute of Science). Isonicotinic acid hydrazide and $\mathrm{L}$ penicillamine at low concentrations inhibited the enzyme but the inhibition was reversed by pyridoxal phosphate or metal. The authors adduced unequivocal evidence to show that the transaminase was a metallo-enzyme. The purification and properties of a naturally occurring inhibitor of glutamine synthesis present in Pongamia galls was described by N. K. Sukanya and C. S. Vaidyanathan (Indian Institute of Science); they also showed the preponderance of this inhibitor in the gall tissue, as compared to normal tissue.

N. Appaji Rao, H. R. Cama and S. A. Kumar (Indian Institute of Science) gave details of some of their recent work on the occurrence of flavin nucleotides in plants and the changes in their concentration with germination of green gram (Phaseolus radiatus) and cow pea (Vigna catiang). The radicle of the germinating seedlings contained almost all the flavin adenine dinucleotide and the major portion of the total flavin, while the cotyledons and the plumules contained flavin mononucleotide as the major flavin. Some interesting examples of species specificity in the mechanism of pyridine nucleotide synthesis by erythrocytes were reported by $P$. G. Tulpule, of the Nutrition Research Laboratories, Hyderabad. Of the seven species studied by them only human and guinea pig erythrocy tes were capable of synthesizing diphosphopyridine nucleotide from nicotinamide and glucose. Human as well as monkey erythrocytes could also synthesize appreciable amounts of diphosphopyridine nucleotide from nicotinic acid and glucose in the presence of glutamine, whereas this metabolic pathway did not seem to operate in the guinea pig. Red blood cells of the monkey were able to synthesize diphosphopyridine nucleotide only in the presence of glutamine, suggesting that nicotinamide was converted to nicotinic acid prior to incorporation in diphosphopyridine nucleotide.

Four special lectures were given in the evenings on each day of the symposium: Dr. D. P. Burma, of the Bose Institute, Calcutta, on "Pentose Phosphate Metabolism", Dr. B. K. Bachhawat (Christian Medical College) on "Purification of Enzymes"; Dr. P. M. Bhargava (Regional Research Laboratories, Hyderabad) on "Protein Synthesis" and Dr. T. Ramasarma (Indian Institute of Science) on "Coenzyme Q". P. S. SARMa

\section{NATIONAL VEGETABLE RESEARCH STATION}

\section{NEW LABORATORY BUILDING}

$\mathrm{T}$ HE new laboratory building of the National Vegetable Research Station was officially opened on October 23 by H.R.H. The Duke of Edinburgh. The decision to establish the Station was taken after the Second World War because of a continuing need to encourage vegetable production in Great Britain, and the Agricultural Research Council is now responsible for government grant-aid to finance the Station and for the general supervision of its scientific programme.

The new building marks the culmination of ten years development from the time when the director, Dr. J. Philp, took over 280 acres of land at Wellesbourne, near Warwick, in September 1949. Initially the site had no electricity, roads or suitable water supplies, and the only buildings were three small cottages and a few farm buildings. Building restrictions in the early years severely hampered development and the research staff had to be housed temporarily in old service huts, while Dutch light structures served as temporary glasshouses.
The new laboratory building was designed by $\mathrm{Mr}$. F. W. Holder, chief architect of the Ministry of Agriculture, Fisheries and Food, and has a total floor area of 33,800 sq. ft. Besides laboratories and offices it contains a library, lecture room and committee room, and the basement has space for the future provision of controlled-environment chambers. The construction uses pre-cast concrete frame and floors with external curtain-walling of insulated plastic and some brickwork, the roof being of copper. The Station also has about a half-acre of glasshouses used for pot-experiments in research projects, a packing shed, implement shed, farm stores and buildings for livestock. 170 acres are served by underground irrigation mains with a borehole for the water source.

The site at Wellesbourne is central for the country as a whole and the soil and climate are suitable for vegetable production, being similar to those in the nearby Vale of Evesham, an important horticultural area. The area of 280 acres, to which 95 acres have 